\title{
Genetic Variability, Character Association and Genetic Divergence in Barley (Hordeum vulgare L.) Genotypes Grown at Horo District, Western Ethiopia
}

\begin{tabular}{|c|c|}
\hline $\begin{array}{l}\text { Jimera Haile }{ }^{1} \text {, Hirpa Legesse }{ }^{2 *} \text { and C.P. Rao }{ }^{2} \\
{ }^{1} \text { Agriculture Office, Horo Guduru Wollega Zone, Horo Guduru, }\end{array}$ & \\
\hline Abstract & Article Infor \\
\hline $\begin{array}{l}\text { Twenty five, diverse six row barley genotypes were evaluated on the basis of yield and yield } \\
\text { related characters at Bako Agricultural Research Center, Shambu sub site. The experiment was } \\
\text { laid down in a Randomized Complete Block Design (RCBD) during } 2012 / 13 \text { cropping season. } \\
\text { The results of the analysis of variance (ANOVA) revealed significance }(P<0.05) \text { differences for }\end{array}$ & $\begin{array}{l}\text { Article History: } \\
\text { Received : } 12-03-2015 \\
\text { Revised : } 17-05-2015 \\
\text { Accepted }: 02-06-2015\end{array}$ \\
\hline $\begin{array}{l}\text { all of the characters, except number of grain yield per spike. This indicated the existence of } \\
\text { variability and hence the potential for selection and improvement. The highest mean grain yield } \\
\text { performance was recorded from genotype IBPmGP } 3 \text {, while the lowest mean performance was } \\
\text { recorded from genotype IBYT-HI16. Thousand seed weight, tiller number per plant, grain yield, } \\
\text { harvest index, spike length and number of kernel per spike were found to have high coefficient } \\
\text { of variability, intermediate to high heritability and genetic advance as percent of the mean, } \\
\text { suggesting that effective and satisfactory selection for practical improvement of these important }\end{array}$ & $\begin{array}{l}\text { Keywords: } \\
\text { Genotype } \\
\text { Character Associations } \\
\text { Clustering } \\
\text { Heritability } \\
\text { Six row } \\
\text { Genetic advance }\end{array}$ \\
\hline $\begin{array}{l}\text { traits is possible. Grain yield showed positive and significant correlations with thousand kernel } \\
\text { weight, biomass yield, and harvest index. Positive associations of Grain yield with yield } \\
\text { components give an opportunity to simultaneously improve yield and yield contributing } \\
\text { characters. In conclusion, the observed variability within the twenty five six row barely } \\
\text { genotypes in grain yield and other agronomic traits, indicates the potential for further } \\
\text { improvement through directional selection and hybridization. }\end{array}$ & $\begin{array}{l}\text { *Corresponding Author: } \\
\text { Hirpa Legesse } \\
\text { E-mail: } \\
\text { hirpa.leg@gmail.com }\end{array}$ \\
\hline
\end{tabular}

\section{INTRODUCTION}

Barley (Hordeum vulgare L.) belongs to the tribe Triticeae of the grass family Poaceae together with other important cereals, wheat and rye. Ethiopia is a secondary centre of diversity for barley (Hordeum vulgare L.), where barley is the third most important cereal crop. Barley is a crop of ancient origin. Its antiquity was documented to the periods of 5000 to 7000 B.C., or earlier (Jena and Neva, 1991). In the world, barley ranks fourth in production among cereals after wheat, rice and maize (Munch, 1992). In Ethiopia, barley is an important cereal crop that is mainly grown by subsistence farmers (Chilot et al., 1998). It is grown in wide range of environments with altitude range of 1500 to 3500 m.a.s.l., but predominantly grown between 2000 to 3500 m.a.s.I.

Barley is most important cereal crop in Oromia region in area coverage as well as production (CSA, 2013). Horo Guduru Wollega, North and west Showa, Arsi, East Wollega, and Bale are major producers of barley in the region. The total area covered by barley is about 448,545 hectares with total production of $8,977,417$ million quintals and the yield of the crop is low with average of $20 \mathrm{q} / \mathrm{ha}$ (CSA, 2013). From this share Horo Guduru Wollega Zone is producing barely on 17,098 hectares with total production of 374,183 of productivity is $21 \mathrm{q} / \mathrm{ha}$ (CSA, 2013).
Barley is one of the major cereal crops grown in Ethiopia. For millennia it has been supplying the basic necessities of life (food, feed, beverages and roof thatching) for many in the Ethiopian highlands. However, the ever-increasing human and livestock populations are placing increasing pressure on the resources in highland environments. Improving productivity and food security in these areas has become imperative. The major breeding objective of barley improvement program in Ethiopia is selection for high seed yield with resistance/tolerance to biotic and a biotic stress among exotic and landrace genotypes (Chilot et al., 1998).

Genetic variability is a prerequisite for an effective selection of any economically important plant species, and a critical survey of genetic variability is essentially aiming at developing high yielding varieties (Akanda et al., 1998). The study of variability and heritability is of primary importance for an efficient breeding program as it provides a genetic basis for effective selections. The type of selection and progress from selection for a particular character depends, in part, on the magnitude of heritability estimates. This is because the expected response under selection is a function of heritability, variation and selection intensity (Ajibade, 2000). Heritability serves as a guide to the reliability of phenotypic success (Hamdi and Erskine, 1990). 
Jimera Haile, Hirpa Legesse and Rao

The potential of a crop to respond favorably to breeding programs depends upon the nature and magnitude of variability, and hence knowledge of the existing genetic variations and the association between various yield traits and their heritability assumes importance (Allard, 1960). Variability is, therefore, prerequisite for plant breeding that effective plant breeding and crop improvement programs depend on the availability of crop genetic diversity. Moreover, the existence of genetic diversity and the association between various yield traits and their heritability is significantly imperative in identifying potential genotypes for future crop improvement. The understanding of the relationships among various traits affecting grain yield is also imperative for the efficacy of selection process (Sharma, 1998).

Little information is available on estimate of genetic variability and genetic relationships using morphological and agronomic traits in part of highlands of Ethiopia for barley genotypes. The present investigation is, therefore, concerned with the estimation of the genetic variability, heritability and correlations among yield and yield components at phenotypic and genotypic levels for designing suitable breeding programs involving six row food barley genotypes. The objective of the study is to assess the genetic variability, genetic diversity and character associations in twenty five, six row food barley genotypes in Horo District, Western Ethiopia.

\section{MATERIALS AND METHODS}

\section{Description of Experimental Site}

The study was conducted at Bako Research Center (BARC) demonstration Shambu sub site which is located in Horo District of Horo Guduru Wollega Zone Oromiya regional state. Horo district is located at $340 \mathrm{~km}$ west of the capital city, Addis Ababa. The study area have an elevation ranging from 2400 m.a.s.I, $8^{0} 10^{\mathrm{N}}$ and $8^{0} 15^{\mathrm{S}}$ latitude and longitude, respectively and with an average minimum and maximum temperature of $10.2^{\circ} \mathrm{C}$ and $25^{\circ} \mathrm{C}$, respectively. The area is also characterized by sub humid agro-ecology with unimodal rainfall pattern with total annual rainfall of $1600 \mathrm{~mm}$, recorded in 2013 cropping season. The rainy season extends from April to November but maximum was received in June, July, August and the type of soil was clay loam with $\mathrm{pH}$ ranging from 7.3 to 7.8 .

\section{Experimental Material}

The experimental materials used consisted of twenty five six row barley genotypes (Hordeum vulgare L.) genotypes(Table 1). All of these genotypes were obtained from Holeta Agricultural Research Center.

\section{Experiment Design and Trial Management}

Twenty five, six row barley genotypes with one standard check variety (HB1307) were used as a treatment. The treatments were arranged in randomized complete block design (RCBD) with three replications. Experimental materials were planted at rate of $125 \mathrm{Kg} / \mathrm{ha}$ $(50 \mathrm{~g} / \mathrm{plot})$ in plot area of $4 \mathrm{~m}^{2}$ with four rows per plot, and with row length of $2.5 \mathrm{~m}$, space between blocks is $1.5 \mathrm{~m}$ and $0.2 \mathrm{~m}$ spacing between rows. Planting date was on the june $14^{\text {th, }}$ of 2013 the main rainy season. Diammonium phosphate (DAP) and urea were applied as per the recommendation. Other agronomic practices were carried out as per the recommendation of the locations.
Sci. Technol. Arts Res. J., April-June 2015, 4(2): 01-09

Table 1: The breeding lines of barley used for the study

\begin{tabular}{|c|c|c|c|}
\hline No & Genotype & Seed source & $\begin{array}{l}\text { Row } \\
\text { type }\end{array}$ \\
\hline 1 & IBON-HI7 & $\begin{array}{c}\text { Holeta } \\
\text { Research } \\
\text { Center }\end{array}$ & Six row. \\
\hline 2 & IBPmGP1 & " & $"$ \\
\hline 3 & IBPmGP2 & $"$ & $"$ \\
\hline 4 & IBPmGP3 & $"$ & $"$ \\
\hline 5 & IBPmGP4 & $"$ & $"$ \\
\hline 6 & IBPmGP5 & $"$ & $"$ \\
\hline 7 & IBPmGP7 & $"$ & $"$ \\
\hline 8 & IBSmutGP1 & $"$ & $"$ \\
\hline 9 & IBSmutGP3 & $"$ & $"$ \\
\hline 10 & IBSmutGP6 & $"$ & $"$ \\
\hline 11 & IBStrGP5 & $"$ & " \\
\hline 12 & IBStrG 6 & $"$ & $"$ \\
\hline 13 & IBStrGP7 & $"$ & $"$ \\
\hline 14 & IBStrGP8 & $"$ & $"$ \\
\hline 15 & IBStrGP9 & $"$ & $"$ \\
\hline 16 & IBYT-HI1 & $"$ & " \\
\hline 17 & IBYT-HI11 & $"$ & " \\
\hline 18 & IBYT-HI12 & $"$ & $"$ \\
\hline 19 & IBYT-HI13 & $"$ & $"$ \\
\hline 20 & IBYT-HI16 & $"$ & $"$ \\
\hline 21 & IBYT-HI2 & $"$ & $"$ \\
\hline 22 & IBYT-HI4 & $"$ & $"$ \\
\hline 23 & IBYT-HI5 & $"$ & $"$ \\
\hline 24 & IBYT-HI8 & $"$ & $"$ \\
\hline 25 & Standard(HB1307) & $\begin{array}{l}\text { Under } \\
\text { production }\end{array}$ & $"$ \\
\hline
\end{tabular}

\section{Data Collected}

The data on the following attributes were collected from the central two rows in each plot/replication of the genotypes.

\section{A. Data Collected Per Plot Basis}

Days to Heading (DH): The number of days from date of sowing to the stage where $75 \%$ of the spike have fully emerged.

Days to Maturity (DTM): The number of days from sowing to the stage when $90 \%$ of the plant in a plot have reached physiological maturity.

Grain yield (GY): Grain yield in $\mathrm{kg} / \mathrm{ha}$ at adjusted to $12.5 \%$ moisture content was recorded.

Thousand Grain Weights (TGW) (g) Kernel Weight: The total weight of one thousand seeds selected at random was weighed in grams for each experimental unit (plot) after adjusted to $12.2 \%$ moisture content.

Above Ground Biomass (BY): This is a sun dry weight of the above ground total plant biomass of harvested crop from two central rows of each plot.

Harvest Index $(\mathrm{HI})$ : On a plot basis, the ratio of weight of dried grain to the weight of dried above ground biomass multiplied by 100 .

Grain Yield per Spike (GYPS): Average numbers of grain yield of spike in $\mathrm{kg} / \mathrm{ha}$ at $12.5 \%$ moisture content will be recorded.

\section{B. Data Recorded on Individual Plant Basis}

Data were recorded randomly by selecting 10 plants from each plot of the central two rows for the following characters.

Tillers/plant (TPP): The average number of tillers per plant for ten randomly took plants in the plot. 
Jimera Haile, Hirpa Legesse and Rao

Effective Tillers/ Plant (PRT): The average number of tillers per plant for ten randomly took plants in the plot which produce grain.

Plant Height (PHT): The average height in $\mathrm{cm}$ measured from the ground level to the tip of the spike excluding the awns at maturity.

Spike Length (SL): The average spike length in $\mathrm{cm}$ from its base to the tips includes awns.

Awn Length: - Long awn on lateral florets/awn less or from seed end to tip measured in cent meter.

\section{Statistical Data Analysis}

Data collected were subjected to analyses of variance (ANOVA) were by using SAS) software (SAS, 2004). The phenotypic correlation coefficients for selected character combination were computed accordingly, as suggested by Dewey and Lu (1959), for selected characters contributing to grain yield.

Variability study estimation of components of variation for analysis of variance, according to RCBD, was done using sampled plants for the characters like plant height, tillers per plant (PTL), Days to heading $(\mathrm{DH})$, days to maturity(DM), number of tiller (NTL), Number Effective of tiller( PRT), and Grain yield/Spike (GYPS), Thousand Seed weight (TGW), Spike length (SL), Awn Length (AWL), Above ground Biomass (BY), Grain yield (GY) and Harvest index $(\mathrm{HI})$ based on their measurements

\section{Estimation of Genetic Parameters}

\section{Estimation of Variance Components}

The phenotypic and genotypic coefficients of variation were estimated according to the method suggested by Burton and de Vane (1953) as follows: -

$$
\begin{aligned}
& \text { Genotypic variance }\left(\sigma_{\mathrm{g}}^{2}\right)=\frac{\mathrm{MS}_{\mathrm{g}}-\mathrm{MS}}{\mathrm{r}} \\
& \text { Where, } \sigma_{\mathrm{p}}^{2}=\text { phenotypic variance } \\
& \sigma_{e}^{2}=\text { Error mean square, } \\
& \mathrm{r}=\text { number of replication } \\
& \text { Phenotypic variance }\left(\sigma_{p}^{2}\right)=\sigma_{g}^{2}+\sigma_{e}^{2} \\
& \text { Where, } \sigma_{\mathrm{p}}^{2}=\text { phenotypic variance and } \\
& \mathrm{r}=\text { number of replication. } \\
& \text { Genotypic coefficient of variability }(\mathrm{GCV})=\frac{\sigma^{2} g}{\bar{x}} X 100 \\
& \bar{x}=\text { Mean value of the trait } \\
& \text { Phenotypic coefficient of variability }(\mathrm{PCV})=\frac{\sigma^{2} p}{\bar{x}} X 100 \\
& \bar{x}=\text { Mean value of the trait. }
\end{aligned}
$$

\section{Estimation of Heritability in Broad Sense}

Broad sense heritability $\left(h^{2}\right)$ expressed as the percentage of the ratio of the genotypic variance $(\sigma 2 g)$ to the phenotypic variance $(\sigma 2 p)$ and was estimated on genotype mean basis as described by Allard (1960) as:

$$
\mathrm{H}^{2}(\%)=(\sigma 2 g / \sigma 2 p) \times 100
$$

\section{Estimation of Genetic Advance}

Genetic advance in absolute unit (GA) and percent of the mean (GAM), assuming selection of superior $5 \%$ of the genotypes was estimated in accordance with the methods illustrated by Johnson et al. (1955) as :GA= Køph2
Sci. Technol. Arts Res. J., April-June 2015, 4(2): 01-09

$$
G A M=(G A / \bar{x}) \times 100
$$

Where, $\mathrm{k}=$ the standardized selection differential at $5 \%$ selection intensity $(K=2.063)$.

\section{Association of Characters}

\section{Estimation of Correlation Coefficients}

Estimation of the phenotypic and genotypic correlation coefficients were done by the procedures suggested by (Miller et al., 1958; Dabholkar, 1992) from corresponding variance and covariance components as:

Phenotypic correlation coefficient

$$
\left(r p_{x y}\right)=\frac{\sigma_{p_{x y}}}{\left(\sqrt{\sigma^{2} p_{x} * \sigma^{2} p_{y}}\right)}
$$

Genotypic correlation coefficient

$$
\left(r g_{x y}\right)=\frac{\sigma_{g_{x y}}}{\left(\sqrt{\sigma^{2} g_{x} * \sigma^{2} g_{y}}\right)}
$$

Where, $r p_{x y}=$ phenotypic correlation coefficient between character $\mathrm{x}$ and $\mathrm{y}$

$r g_{x y}=$ genotypic correlation coefficients between character $\mathrm{x}$ and $\mathrm{y}$

The significance of phenotypic correlation coefficients was tested by the formula of Singh and Chaudhary (1985).

$$
t^{\prime}=r p_{x y} * \sqrt{g-2 /\left(1-r p^{2}{ }_{x y}\right)}
$$

$\mathrm{t}$ ' value was tested against the tabulated $\mathrm{t}$-value for ( $\mathrm{g}$ 2 ) degree of freedom where $g$ is the number of genotypes studied.

Whereas the significance of genotypic correlation coefficient is tested using the formula described by Robertson (1959) indicated as ${ }^{\prime} t^{\prime}=\frac{r g_{x y}}{S E_{g y}}$ and $S E=\sqrt{\frac{1-r_{g y y}^{2}}{2 h x^{*} h y}}$ where $\mathrm{hx}=$ heritability of trait $\mathrm{x}$, hy $=$ heritability of trait $\mathrm{y}$, $g=$ number of genotypes and rgxy =genotypic correlation coefficient. Thus, the calculated value is compared with tabulated' value at $\mathrm{g}-2$ degrees of freedom at $5 \%$ and $1 \%$ level of significance.

\section{RESULTS AND DISCUSSION}

\section{Analysis of Variance}

The results of analysis of variance for yield and yield related characters are presented in Table 2. The analysis of variance showed a highly significant $(P<0.01)$

\begin{tabular}{|c|c|c|c|c|c|c|c|c|c|c|c|c|c|}
\hline Sources & DF & DH & DM & $\mathrm{PH}$ & PRT & NTL & GYPS & SL & AWL & THSW & $\mathrm{HI}$ & BY & GY \\
\hline Replication & 2 & 0.69 & 5.3 & 9.12 & $38.18^{* *}$ & $54.6^{* *}$ & $1140.32^{* *}$ & 1.23 & 0.88 & 46.63 & 0.0004 & 0.504 & 0.13 \\
\hline Treatment & 24 & $14.7^{*}$ & $5.8^{* *}$ & $292.3^{* *}$ & $7.9^{* *}$ & $5.97^{\star *}$ & $153.1^{\mathrm{ns}}$ & $1.47^{*}$ & $2.89^{* *}$ & $74.04^{\star *}$ & $0.004^{* *}$ & $2.46^{\star *}$ & $2.46^{* \star}$ \\
\hline Error & 48 & 1.78 & 2.41 & 19.09 & 1.42 & 2.34 & 102.9 & 0.82 & 0.37 & 18.51 & 0.0012 & 0.66 & 0.09 \\
\hline
\end{tabular}
differences for most of the characters, except for grain yield per spike indicating the existence of variability among the genotypes under study. The significance of genotype difference indicates the presence of variability for each of the characters among the tested entries. In line with this study, Nigussie (2001) also evaluated 36 accessions of Ethiopian Barley, for several characters and reported existence of enormous amount of genetic variability. Similar results were reported by Singh et al. (1990) that all agronomic parameters showed a highly significant variation $(P<0.01)$ for the tested genotypes except grain yield per spike. Balcha (2002) observed the existence of high variability in barley genotypes for grain yield and agronomic traits studied.

Table 2: Mean squares from analysis of variance of grain yield and other related characters in 25 barley genotypes 
Jimera Haile, Hirpa Legesse and Rao

Higher grain yield was recorded from IBPmGP3, IBSmutGP1 and IBYT-HI1, whereas IBYT-gave the lowest grain yields. Heavier thousand seed weight was recorded from genotypes IBYT-HI11 and IBYT-HI13, and lighter seed weight was rewarded from IBStrGP9 and IBYT-HI1
Sci. Technol. Arts Res. J., April-June 2015, 4(2): 01-09

(Table 3). The significant differences among barley genotypes under investigation indicate the presence of genetic variability in the material used and provide a good opportunity for yield improvement.

Table 3: Mean performance of 25 barley genotypes evaluated for grain yield and other related characters

\begin{tabular}{|c|c|c|c|c|c|c|c|c|c|c|c|c|c|}
\hline S.N & Genotypes & DH & DM & PH & PRT & NTL & GYPS & SL & AWL & THSW & $\mathrm{HI}$ & BY & GY \\
\hline 1 & IBON-HI 7 & 62.3 & 119.3 & 93.3 & 9.4 & 11.7 & 74.8 & 10.6 & 15.1 & 35.8 & 0.36 & 6.28 & 3.54 \\
\hline 2 & IBPmGP 1 & 63.7 & 123.0 & 92.0 & 11.5 & 14.6 & 59.7 & 8.5 & 15.7 & 41.5 & 0.34 & 4.26 & 2.16 \\
\hline 3 & IBPmGP 2 & 61.7 & 119.7 & 95.7 & 10.2 & 12.1 & 59.5 & 8.3 & 15.9 & 50.4 & 0.38 & 5.23 & 3.26 \\
\hline 4 & IBPmGP 3 & 63.3 & 121.5 & 112.3 & 12.8 & 14.2 & 74.3 & 9.3 & 13.4 & 39.1 & 0.37 & 7.92 & 4.62 \\
\hline 5 & IBPmGP 4 & 65.7 & 121.6 & 90.3 & 11.7 & 14.0 & 64.8 & 9.1 & 14.1 & 41.5 & 0.37 & 5.90 & 3.53 \\
\hline 6 & IBPmGP 5 & 61.3 & 117.0 & 106.7 & 11.2 & 13.6 & 48.7 & 8.4 & 13.3 & 37.7 & 0.36 & 6.03 & 3.5 \\
\hline 7 & IBPmGP 7 & 59.7 & 118.0 & 95.7 & 11.6 & 13.5 & 66.6 & 9.33 & 15.1 & 39.2 & 0.36 & 4.46 & 2.55 \\
\hline 8 & IBSmutGP1 & 63.6 & 119.3 & 98.7 & 11.5 & 12.6 & 61.1 & 8.3 & 13.4 & 40.5 & 0.38 & 6.93 & 4.25 \\
\hline 9 & IBSm & 61.0 & 119.0 & 105.3 & 10.5 & 12.6 & 56.9 & 8.8 & 14.5 & 37.6 & 0.35 & 6.07 & 3.23 \\
\hline 10 & IBSm & 61.6 & 121.0 & 96.7 & 7.9 & 10.5 & 68.9 & 9.4 & 15.5 & 37.6 & 0.34 & 6.78 & 3.58 \\
\hline 11 & IBStrGP 5 & 61.6 & 119.6 & 94.0 & 10.9 & 12.4 & 58.9 & 7.4 & 13.4 & 47.8 & 0.33 & 6.48 & 3.29 \\
\hline 12 & IBStr & 62.3 & 121.3 & 111.7 & 11.4 & 13.0 & 58.8 & 8.5 & 14.7 & 47.3 & 0.36 & 5.80 & 3.27 \\
\hline 13 & IBStrGP 7 & 65.0 & 120.0 & 91.7 & 8.6 & 10.3 & 71.6 & 8.9 & 15.3 & 40.8 & 0.37 & 5.95 & 3.52 \\
\hline 14 & IBStrGP 8 & 63.7 & 118.6 & 110.3 & 8.0 & 10.6 & 73.3 & 9.3 & 12.7 & 41.0 & 0.38 & 5.31 & 3.31 \\
\hline 15 & IBStrGP 9 & 60.0 & 117.3 & 106.0 & 11.5 & 13.3 & 68.6 & 8.5 & 14.2 & 32.9 & 0.35 & 6.47 & 3.52 \\
\hline 16 & IBYT-HI 1 & 67.7 & 121.0 & 98.7 & 7.0 & 9.7 & 63.3 & 9.3 & 12.5 & 34.3 & 0.39 & 6.25 & 4.12 \\
\hline 17 & IBYT & 64.0 & 120.0 & 103.6 & 8.6 & 11.2 & 51.3 & 8.7 & 16.1 & 49.4 & 0.38 & 5.7 & 3.5 \\
\hline 18 & IBYT-HI 12 & 66.0 & 120.3 & 111.7 & 9.8 & 11.7 & 65.3 & 8.3 & 13.4 & 42.4 & 0.35 & 4.90 & 2.64 \\
\hline 19 & IBYT-HI 13 & 62.0 & 118.3 & 101.0 & 7.4 & 10.0 & 68.7 & 7.9 & 14.3 & 48.7 & 0.36 & 6.32 & 3.62 \\
\hline 20 & IBYT-HI 16 & 64.0 & 119.0 & 92.3 & 9.9 & 12.0 & 60.8 & 8.1 & 14.9 & 37.6 & 0.25 & 4.04 & 1.40 \\
\hline 21 & IBYT-HI 2 & 61.6 & 119.3 & 97.0 & 8.4 & 10.8 & 63.6 & 7.8 & 14.3 & 44.4 & 0.34 & 4.48 & 2.35 \\
\hline 22 & IBYT-HI 4 & 67.0 & 120.7 & 107.6 & 5.3 & 11.1 & 66.7 & 7.5 & 13.9 & 47.8 & 0.27 & 6.40 & 2.47 \\
\hline 23 & IBYT-HI 5 & 67.6 & 120.3 & 127.3 & 7.8 & 10.7 & 54.3 & 8.6 & 13.3 & 41.0 & 0.34 & 6.16 & 3.19 \\
\hline 24 & IBYT-HI 8 & 65.0 & 119.6 & 94.0 & 10.8 & 12.2 & 66.6 & 8.0 & 13.9 & 44.4 & 0.3 & 5.67 & 2.37 \\
\hline 25 & Local check & 65.0 & 120.3 & 123.3 & 9.5 & 10.4 & 74.8 & 8.7 & 13.9 & 47.8 & 0.29 & 5.31 & 2.18 \\
\hline & Mean & 63.5 & 119.8 & 102.3 & 9.9 & 11.9 & 64.1 & 8.6 & 14.3 & 41.9 & 0.35 & 5.8 & 3.2 \\
\hline & LSD (0.05) & 2.2 & 2.6 & 7.2 & 1.9 & 2.5 & 16.7 & 1.5 & 0.99 & 7.1 & 0.1 & 1.34 & 0.48 \\
\hline & CV (\%) & 2.1 & 1.3 & 4.3 & 12.1 & 12.8 & 15.8 & 10.5 & 4.3 & 10.3 & 9.91 & 14.03 & 9.23 \\
\hline
\end{tabular}

$\mathrm{DH}=$ Days to heading; DM = days to maturity; PH = Plant height; NTL= number of tiller; PRT = Number effective tillers; GYPS = Grain yield per spike; TGW = Thousand seed weight; $S L=$ Spike length; $A W L=$ Awn length; $B Y=$ above ground biomass (t/ha); $G Y=G r a i n$ yield (t/ha) and $\mathrm{HI}=$ Harvest index

\section{Genetic Variability}

In trying to determine the extent to which variation in yield components are responsible for differences in yield among various cultivars, it must be borne in mind that overall variability depends on genetic (g) and environmental (e) components (Allard et al., 1960). While coefficients of variation measure the magnitude of variability present in a population, estimates of heritability and genetic advances are important preliminary steps in any breeding program as they provide information needed in designing the most effective breeding program and the relative practicability of selection. The range, mean performance, genotypic variance, phenotypic variance, genotypic coefficient of variability (GCV), phenotypic coefficient of variability (PCV), broad sense heritability, genetic advance and genetic advance expressed as percentage of mean for 12 characters are presented in Table 4.

\section{Range and Mean Performance for Characters}

Among the characters under investigation, a wide range was recorded for grain yield, effective tillers, days to heading, days to maturity, plant height and thousand- kernel weight (Table 4). This result was in harmony with reports of ICARDA (2004) that noted wide range of variations in days to maturity, plant height, days to heading, and 1000-seed weight in barley genotypes. Likewise, Alam, et al., (1992) reported 62-97 days to maturity and 70.5-112.2 cm days for heading and plant height, respectively. Lakew et al. (1997) also reported a wide range of variation for days to heading (96-116), maturity $(137-174)$, plant height $(80-140 \mathrm{~cm})$ and grain yield (4.202-4.71 t/ha). On the contrary, a narrow range was recorded for spike length and awns length. The highest grain yield (4.62 t/ha) was recorded from IBPmGP 3 genotype, while the lowest yield of $(1.40 \mathrm{t} / \mathrm{ha})$ was obtained from at IBYT-HI 16, suggesting the presence of variability for desired traits and amount of variation for different parameters. Similar results of wide range of variation for different characters were recorded by Munch, (1992).

\section{Phenotypic and Genotypic Coefficients Variations}

The estimates of genotypic coefficient of variation (GCV) and phenotypic coefficient of variation (PCV) were high for grain yield per spike, grain yield, thousand seed 
Jimera Haile, Hirpa Legesse and Rao

weight, plant height, biological yield, number of effective tillers and number of tillers(Table 4). The results revealed considerable phenotypic and genotypic variances among the genotypes for the traits under consideration. In most traits, namely days to heading, plant height, number of effective tillers, awn length, grain yield, biological yield and harvest index $(\mathrm{HI})$, a large portion of the phenotypic
Sci. Technol. Arts Res. J., April-June 2015, 4(2): 01-09

variance was accounted for by the genetic component and the contributions of genetic variance to phenotypic variance were more than $80.1 \%$. In the contrary, a large portion of the phenotypic variance was accounted for by the environment component and the contributions of environmental variance to phenotypic variance were more than $127 \%$ in the remaining traits (Table 4 ).

Table 4: The range, mean performance, genotypic variance, phenotypic variance, genotypic coefficient of variability $(\mathrm{GCV})$, phenotypic coefficient of variability (PCV), broad sense heritability, genetic advance and genetic advance expressed as percentage of mean

\begin{tabular}{cccccccccccc}
\hline S.N & Characters & Range & Mean & $\mathbf{S E} \mathbf{\pm}$ & $\boldsymbol{\sigma}^{2} \mathbf{g}$ & $\mathbf{\sigma}^{2} \mathbf{p h}$ & $\mathbf{h}^{\mathbf{2}} \mathbf{( \% )}$ & $\mathbf{G C V}(\%)$ & $\mathbf{P C V}(\%)$ & $\mathbf{G A}$ & $\mathbf{G A M}$ \\
\hline 1 & DH & $59.7-67.7$ & 63.6 & 1.33 & 4.3 & 6.1 & 70.8 & 6.8 & 9.6 & 3.79 & 5.96 \\
2 & DM & $117.0-123.0$ & 119.8 & 1.55 & 1.11 & 3.5 & 31.5 & 0.9 & 2.9 & 1.16 & 0.96 \\
3 & PHT & $90.3-127.3$ & 102.3 & 4.36 & 70.1 & 89.1 & 78.6 & 68.5 & 87.4 & 15.28 & 14.9 \\
4 & PRT & $5.3-12.8$ & 9.9 & 1.19 & 2.7 & 3.6 & 60.4 & 22.0 & 36.4 & 3.35 & 33.9 \\
5 & NTL & $9.7-14.6$ & 11.9 & 1.53 & 1.2 & 3.6 & 34.1 & 10.1 & 29.7 & 0.77 & 6.4 \\
6 & GYPS & $48.7-74.8$ & 64.1 & 10.14 & 16.7 & 119.5 & 13.9 & 26.1 & 186.7 & 4.9 & 7.7 \\
7 & SL & $7.4-10.6$ & 8.6 & 0.90 & 0.21 & 1.03 & 20.38 & 2.43 & 11.9 & 0.42 & 4.8 \\
8 & AWL & $12.5-16.1$ & 14.3 & 0.60 & 0.84 & 1.2 & 70.0 & 5.9 & 8.4 & 1.58 & 11.1 \\
9 & THSW & $32.9-50.4$ & 41.9 & 4.30 & 18.5 & 37.2 & 49.8 & 44.1 & 88.6 & 6.25 & 14.9 \\
10 & GY & $1.4-4.6$ & 3.2 & 0.29 & 0.5 & 0.59 & 84.3 & 15.8 & 18.8 & 1.33 & 42.0 \\
11 & BY & $4.1-7.9$ & 5.8 & 0.81 & 2.2 & 2.89 & 77.2 & 38.4 & 49.8 & 2.7 & 46.6 \\
12 & HI & $0.25-0.39$ & 0.35 & 0.03 & 0.008 & 0.02 & 40.0 & 2.28 & 5.7 & 0.12 & 34.3 \\
\hline
\end{tabular}

$\mathrm{PH}=$ Plant height; $\mathrm{DH}=$ Days to heading; DM = days to maturity; NTL= number of tiller; PRT = Number effective of tillers; GYPS $=$ Grain yield per spike; TGW = Thousand seed weight; SPS = Spikelet per spike; SL = Spike length; AWL = Awn length; BY = above ground biomass; $\mathrm{GY}=$ Grain yield, $\mathrm{HI}=$ Harvest index

Genotypic coefficient of variation (GCV) and phenotypic coefficients of variation (PCV) values of roughly more than $20 \%$ are considered to be high, and values less than $10 \%$ low and values in between as medium. The estimates of genotypic coefficient of variation (GCV) were high for plant height (68.48), thousand seed weight (44.13), biological yield (38.4), grain yield per spike (26.12), and number of effective tillers (22.0). The remaining traits recorded moderate to low genotypic coefficient of variation (GCV) estimates. In agreement of this Alderfasi (2001) reported higher values of GCV combined with higher values of heritability which resulted in higher genetic advance as percentage of mean for seeds per spike (21.7\%), spike length (21.7\%), number of heads per square meter $(30 \%)$, and grain yield per spike (30\%). In reverse way Deshmukh et al. (1986), reported also low genotypic coefficient of variation (GCV) estimates. The genotypic coefficients of variation (GCV) values were lower than phenotypic coefficients of variation $(P C V)$ values for all the traits with great differences which reflect the influence of environment on the expression of traits (Table 4). But thousand seed weight, awn length and productive tillers per plant showed negative correlation with dependent characters grain yield.

These results are in agreement with the findings of Balcha (2002), and Getachew et al. (1993), but disagree with that of Desalegn et al. (2000). The weak associations of grain yield with tillers per plant imply that reduced number of tillers in less favorable environments could increase yield. This may be due to the high-energy loss for the production of biomass than starch to produce grain yield within short growing season. This result agrees with the reports of Donald (1981).

\section{Heritability}

Heritability and genetic advance are important selection parameters. Heritability estimates along with genetic advance are normally helpful in predicting grain yield under selection than heritability estimates alone (Singh, 1993). In Singh study, broad sense heritability $\left(h^{2}\right)$ estimate varied from $40 \%$ for susceptibility to scald to $89 \%$ for susceptibility to lodging. In the whole, susceptibility to lodging, days to heading and maturity, and spikelet per spike demonstrated high heritability estimates (>75\%). Similarly, Assefa (2003) reported higher value of heritability for days to maturity, spike length and number of seeds per spike. Heritability estimates is used in conjunction with selection differential and heritability is accompanied with a good level of GCV (Burton and De Vane, 1953) to predict advance from selection for testing program is essential.

Estimated heritability (broad sense heritability) for the characters considered is presented in Table 5. The heritability values were sufficiently high for most of the traits, indicating the possibility of progress from selection. The high heritability values for most of the characters could be attributed to the relatively small environmental variability for the location. Heritability estimates, in a broad sense, for various traits ranged from 13.98 to $84.3 \%$. The results of heritability indicated that moderate heritability values were recorded for thousand seed weight (49.75\%) and harvest index $(40 \%)$. Low heritability values were recorded for spike length $(20.38 \%)$, days to maturity $(31.5 \%)$, number of tillers per plant $(34.08 \%)$, and grain yield per spikes $(13.98 \%)$. High heritability values were obtained for other yield components, namely grain yield (84.3\%), biological yield $(77.16 \%)$, plant height $(78.58 \%)$, days to heading $(70.84 \%)$, awn length $(70 \%)$, and number of effective tillers $(60.44 \%)$ was observed, higher heritability value values is greater than $60 \%$, low heritability value is less than $40 \%$, medium heritability values is between $40 \%-60 \%$ as reported by previous workers ICARDA, (1990) 
Table 5: Distribution of barley genotypes in different clusters

\begin{tabular}{|c|c|c|c|c|c|c|}
\hline \multicolumn{7}{|c|}{ Number of clusters } \\
\hline \multirow{9}{*}{ 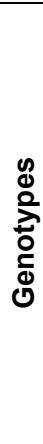 } & Cluster I & Cluster II & Cluster III & Cluster IV & Cluster V & Cluster VI \\
\hline & IBON-HI 7 & IBPmGP 5 & IBPmGP 2 & IBPmGP 3 & IBPmGP 5 & IBYT-HI 5 \\
\hline & IBPmGP 1 & & IBStrGP 5 & IBStrGP 8 & IBSmutGP 3 & HB 1307 \\
\hline & IBPmGP 7 & & IBYT-HI 11 & IBYT-HI 12 & IBStrGP 9 & \\
\hline & IBSmutGP 1 & & IBYT-HI 13 & IBStrGP 6 & & \\
\hline & IBPmGP 4 & & IBYT-HI 2 & IBStrGP 6 & & \\
\hline & IBSmutGP 6 & & IBYT-HI 8 & & & \\
\hline & IBSmutGP 6 & & & & & \\
\hline & IBYT-HI 16 & & & & & \\
\hline
\end{tabular}

Hence, a good progress can be made if some of these traits are considered as selection criteria. Generally, higher heritability estimates (for seven characters out of 12) were recorded. If heritability of a character is high, say $60 \%$ or more, selection for such a character should be fairly easy, because there would be a close correspondence between genotype and phenotype due to a relatively contribution of environment to phenotype. But for a character with low heritability, less than $40 \%$, selection may be considerably difficult or virtually impractical due to the masking effect of the environment on genotypic effects similarly high heritability estimates were also obtained for days to heading, 1000-seed weight, plant height and grain yield by Major and Singh (1996) on the other hand thousand seed weight of plant and biomass per plant exhibited low heritability estimates present investigation, Similarly De et al. (2000) reported high heritability values for seeds yield and plant height. These results suggest the importance of additive gene action for their inheritance, and improvement could be brought about by a phenotypic selection (Johnson et al., $1955 \mathrm{~b}$ ) also observed moderate to high heritability values for 1000 seed weight, number of pods per plant and Number of secondary branches per plant.

\section{Character Associations}

Grain yield is the most complex trait and it is influenced by many factors (known and unknown) that determine productivity. Therefore, understanding of the inheritance and interrelation ships of grain yield and characters influencing these traits are highly important for formulating selection criteria. Thus, estimation of the magnitudes of genotypic and phenotypic correlations of grain yield and its components and among yield related traits are highly crucial to utilize the existing variability through selection. In practical breeding work, the improvement of a target traits can be achieved through indirect selection via other characters this needs a good knowledge of the association of the different characters with the target trait and among the different characters themselves (Kassaye, 2006).

\section{Phenotypic and Genotypic Correlation for Grain Yield and Yield Related Traits}

Correlations of characteristics among yield, its components, and other economical traits are important for making selection in breeding program. Correlation coefficient analysis measures the mutual relationship between various plant characteristics and determines the component characters on which selection can be based for improvement in yield. Yield, in general, is a complex polygenic trait and difficult to improve directly. Estimating its genotypic and phenotypic correlation coefficients with yield related traits is important to utilize the available variability through selection.

The comparison of the coefficients showed that estimates of genotypic correlation coefficient (rg) are generally higher in magnitude than those of phenotypic correlation coefficient (rph). This revealed that association among these characters was under genetic control. Table 5 shows the phenotypic correlation coefficients of grain yield with different yield related characters. The phenotypic correlation coefficients were smaller than the corresponding genotypic correlation coefficients signifying that most of the association existed between grain yield and other traits were controlled by genetic factor.

Out of twelve traits, grain yield (GY) had significant phenotypic correlation coefficient (rph) with both biological yield (BY) and harvest index (HI) (Table 6). On the other hand, grain yield (GY) had positive non-significant association with very small relative magnitude of the phenotypic correlation coefficients with most of the traits such as days to maturity (DM), plant height $(\mathrm{PH})$, number of tiller (NTL), number of effective tillers (PRT), grain yield per spike (GYPS), spike length (SL), above ground biomass (BY) and harvest index $(\mathrm{HI})$ considered in the current study signifying that simultaneous selection of these traits is possible without affecting each other similarly significant positive correlation of tillers per plant with yield per plant have been reported, that of number of grains per spike by Mondal et al. (1997).

Moreover, grain yield had negative non-significant association with days to heading $(\mathrm{DH})$, awn length (AWL) and thousand seed weight (THSW) traits reflecting that selection of genotypes for longer days to heading, higher thousand seed weight and awn length would result in lower grain yield because of their negative association existed between them Equally, Singh et al. (1979) found seed yield to be significantly associated with plant height, 1000 -seed weight. Harvest index (HI) had positive and significant phenotypic correlation coefficient with spike length (SL) only, but negative non-significant phenotypic correlation coefficient with all remaining traits except for thousand seed weight (THSW) which showed positive non-significant correlation coefficient, implying that simultaneous selection of these two traits for crop improvement is impossible without affecting each other. 
Table 6: Mean values of six clusters for different characteristics

\begin{tabular}{ccccccccccccc}
\hline GROUP & DH & DM & PHT & PRT & NTL & GYPS & SL & AWL & THSW & GY & BY & HI \\
\hline Cluster I & 63.2 & 120.2 & 93.8 & 10.3 & 12.4 & 66.1 & 9.0 & 14.9 & 39.3 & 3.1 & 5.5 & 0.34 \\
Cluster II & 67.7 & 121.0 & 98.7 & 7.0 & 8.6 & 63.3 & 9.3 & 12.5 & 34.3 & 4.1 & 6.3 & 0.39 \\
C luster III & 62.7 & 119.4 & 97.6 & 9.4 & 11.5 & 61.4 & 8.0 & 12.4 & 47.5 & 3.1 & 5.6 & 0.34 \\
Cluster IV & 64.4 & 120.5 & 110.7 & 10.1 & 12.1 & 67.7 & 8.6 & 13.6 & 43.5 & 3.3 & 6.1 & 0.34 \\
Cluster V & 66.3 & 120.2 & 125.3 & 8.6 & 10.6 & 64.5 & 8.6 & 13.6 & 44.4 & 2.7 & 5.7 & 0.31 \\
Cluster VI & 60.9 & 117.7 & 105.9 & 11.1 & 13.1 & 58.1 & 8.6 & 14.9 & 36.1 & 3.4 & 6.2 & 0.35 \\
\hline
\end{tabular}

$\mathrm{PH}=$ Plant height, $\mathrm{DH}=$ Days to heading, DM = Days to maturity, NTL $=$ Number of tiller, PRT $=$ Number effective of tiller, GYPS $=$ Grain yield per pike, TGW = Thousand seed weight, $\mathrm{SPS}=$ Spikelet per spike, SL $=$ Spike length, $\mathrm{AWL}=\mathrm{Awn}$ length, $\mathrm{BY}=\mathrm{Above}$ ground biomass, $\mathrm{GY}=$ Grain yield, $\mathrm{HI}=$ Harvest index .

Biological yield (BY) had negative and significant phenotypic correlation coefficient with awn length (AWN), and negative non-significant phenotypic correlation coefficient with spike length (SL), and thousand seed weight (THSW), while it had positive non-significant phenotypic correlation coefficient with all other traits except for grain yield (GY) Singh et al. (1990) found positive correlation of harvest index with days to heading, days to maturity this is not in harmony with the present result. Thousand seed weight (THSW) had positive significant phenotypic correlation coefficient with awn length (AWL) but it had negative significant phenotypic correlation coefficient with spike length (SL).Awn length (AWL) had negative significant phenotypic correlation coefficient with days to heading $(\mathrm{DH})$ and plant height $(\mathrm{PH})$. The result also indicated that awn length (AWL) had positive non-significant phenotypic correlation coefficient with days to maturity (DM), number of effective tillers (PRT), number of tillers (NTL) and spike length (SL).

Grain yield per spike had positive significant phenotypic correlation coefficient with spike length (SL) only. Number of tillers (NTL) had the largest positive and significant phenotypic correlation coefficient with number of effective tillers (PRT) but it had negative significant positive phenotypic correlation coefficient with days to heading $(\mathrm{DH})$. In the present study genotypic correlations were estimated as they elucidate true association by excluding the environmental influence (Table 6). At genotypic level, grain yield had high positive and significant with harvest index $(\mathrm{HI})$ and biological yield (BY). On the other hand, grain yield had positive nosignificant genotypic correlation coefficient with most of the characters under investigation and negatively nonsignificantly correlated with awn length (AWL), thousand seed weight (THSW) and days to maturity (DM). Spike length (SL) had negative significant genotypic correlation coefficient with thousand seed weight (THSW) but it had positive significant correlation coefficient with harvest $(\mathrm{HI})$, grain yields (GY) and grain yield per spike (GYPS). The result indicated that awn length (AWL) had negative significant with days to heading $(\mathrm{DH})$ and plant height (PH). Number of tillers (NTL) had the largest positive and significant genotypic correlation coefficient with number of effective tillers (PRT) only.

Both at phenotypic as well as genotypic levels, in general, grain yield (GY) had positively significantly correlated with biological yield (BY) and harvest index $(\mathrm{HI})$. The present study in agreement with those positive associations between grain yields with Harvest index, biological yield. a negative association with days to heading were obtained by (Gashaw, 2007), In the same approach, number of tillers (NTL) had the largest positive significant correlation coefficient with number of effective tillers (PRT) at both phenotypic as well as genotypic levels. Spike length (SL) had positively and significantly correlated with harvest index (HI) but negatively significantly correlated both at phenotypic as well as genotypic levels. Thousand seed weight (THSW) had negative significant correlation both at phenotypic as well as genotypic levels but negatively significantly correlated only at phenotypic level. Apart from the aforementioned traits, either positively or negatively associated traits, all the remaining traits indicated insignificant association. Various barley trait associations that are in some cases in agreement with the present findings have previously been reported by various workers e.g. (Falconer and Mackay, 1996; (Johnson et al., 1955b), took 10 random plant samples from five varieties of barley and studied several attributes found seed yield to be significantly associated with plant height, number of tillers, 1000-seed weight. Genotypic correlation to phenotypic correlation were greater than the corresponding correlation coefficients, and this suggested that the apparent associations might be largely due to genetic causes and the environment played least role in the associations.

The tested genotypes had $D$-square values ranged from $0.54-11.82$, indicating the presence of divergence among the 25 barley genotypes. As per average D-square values genotypes IBStrGP7 (11.82), IBStrGP6 (11.67), IBPmGP3 (11.57) and IBStrGP5 (11.41) were on an average maximum divergent from all the tested genotypes. While genotypes IBYT-HI-13 (0.78), IBYT-HI1(0.54), IBPmGP7 (0.52), IBPmGP4 (0.36), were some the least divergent genotypes. The tallest genotypes viz., IBPmGP5, IBSmutGP3 and IBStrGP9 representing cluster $V$ with recorded mean plant height of $125.3 \mathrm{~cm}$, whereas the shortest mean plant height $93.82 \mathrm{~cm}$ was recorded for cluster I that is represented by genotypes IBON-HI7, IBPmGP1, IBPmGP7, IBSmutGP1, IBPmGP4, IBSmutGP6, IBSmutGP6, IBYT-HI16 genotypes Other tall varieties were grouped in cluster IV $(110.75 \mathrm{~cm})$, and VI $(105.9 \mathrm{~cm})$.

Cluster II exhibited highest harvest index (0.39) and the lowest on cluster $V(0.31)$. The range of days to maturity was between 117 to 123 days for cluster VI and I, respectively. Maximum thousand-seed weight (50.36) was in cluster III while the lowest was in cluster V (30.95). Maximum biological yield was recorded for cluster IV (7.92.) but minimum biological yield for cluster I (4.04). The highest grain yield was recorded for cluster II (4.62) while lowest grain was recorded for cluster $V(1.40)$. Other clusters with high grain yield were cluster VI (3.41) and cluster IV (3.26). Moderate divergence among the genotypes was due to the fact that they were developed 
Jimera Haile, Hirpa Legesse and Rao

at different time with repeated crossing and selection from genetically different parents for similar purposes. This demonstrated the usefulness of divergence analysis before hybridization program starts and it reduces unnecessary wastage of time and resources.

Moreover, having high intra-cluster distances and coefficient of variation are good indicators for the presence of variability among the barley landraces within
Sci. Technol. Arts Res. J., April-June 2015, 4(2): 01-09

each cluster. The result is supported by earlier studies (Asfaw, 1989; Abebe et al., 2010). High inter-and intracluster distances indicate that barley landraces in each cluster are variable, and selection of landraces both within and between clusters may be bringing about high genetic gain for the characters considered. Highest inter-cluster distance was observed in cluster $V(8.722)$ followed by cluster III (8.428). The minimum inter cluster distance was observed cluster IV (1.123).

Table 7: Clusters standard deviations values of six clusters for different characteristics

\begin{tabular}{llllllllllllr}
\hline GROUP & DH & DM & PHT & PRT & NTL & GYPS & SL & AWL & THSW & GY & BY & HI \\
\hline Cluster I & 3.08 & 1.53 & 5.1 & 1.9 & 1.6 & 3.97 & 0.69 & 1.12 & 3 & 0.8 & 0.5 & 0.2 \\
Cluster II & 1.56 & 1.4 & 2.75 & 1.1 & 1.2 & 2.79 & 0.49 & 0.92 & 4.2 & 1.1 & 0.9 & 0.04 \\
C luster III & 2.26 & 1.17 & 4.74 & 1.8 & 0.74 & 3.5 & 0.74 & 0.69 & 3.8 & 0.7 & 0.54 & 0.5 \\
Cluster IV & 1.17 & 0.8 & 7.7 & 2.4 & 2.7 & 0.37 & 0.47 & 0.35 & 6.2 & 1.8 & 1.7 & 0.05 \\
Cluster V & - & - & - & - & - & - & - & - & - & - & - & - \\
Cluster VI & 1.34 & 1.8 & 3.4 & 1.2 & 1.1 & 4.7 & 0.18 & 1.2 & 6.24 & 0.17 & 0.14 & 0.01
\end{tabular}

$\mathrm{PH}=$ Plant height, $\mathrm{DH}=$ Days to heading, $\mathrm{DM}=$ days to maturity, NTL= number of tiller, PRT =Number Effective of tiller, GYPS=Grain yield/Spike, TGW= Thousand Seed weight, SPS =Spikelet per spike, SL =Spike length, AWL =Awn Length, BYTHA =above ground Biomass, $\mathrm{GY}=$ Grain yield, $\mathrm{HI}=$ Harvest index.

Highest inter-cluster distance was observed in cluster $\mathrm{V}$ (8.722) followed by cluster III (8.428). The minimum inter cluster distance was observed cluster IV (1.123). Generally the result showed that the genotypes introduced from Holeta Agricultural research Center for selection trial of Horo areas moderately divergent. Crosses involving parents belonging to most divergent clusters would be expected to manifest maximum heterosis and wide variability in genetic architecture (Singh et al., 1987).

\section{CONCLUSIONS}

In this study, 25 six row barley genotypes were evaluated in randomized complete block design at Bako Research Center, Shambu sub site with the objective of estimating the genetic variability and character associations among yield and yield component traits among barley genotypes, to cluster genetically into different groups and to select the most promising one(diverse parents for utilization in breeding program)so analysis of variance showed the presence of highly significant $(p<5 \%)$ differences among the tested genotypes for many characters considered, except Grain yield per spike indicating the existence of variability among the tested genotypes for these characters.

Heritability estimates range from $13.89 \%$ grain yield per spike to 84.3 for grain yield .high heritability estimate observed for days to heading, 1000-seed weight, and plant height, biomass per plot, awn length, and harvest index. The expected Genetic advance as percent of the mean (GAM) was varied from $0.96 \%$ for days to maturity $46.58 \%$ for biomass per plot, High heritability was coupled with high GAM for biomass per plot, seed yield per plot.

Generally, genotypic correlation was higher than the corresponding phenotypic ones; this implied that, the trial under consideration was genetically controlled and the environment had least effect on correlated characters. Correlations of characteristics among yield, its components, and other economical traits are important for making selection in breeding program. Correlation coefficient analysis measures the mutual relationship between various plant characteristics and determines the component characters on which selection can be based for improvement in yield. Yield, in general, is a complex polygenic trait and difficult to improve directly. Estimating its genotypic and phenotypic correlation coefficients with yield related traits is important to utilize the available variability through selection.

Both at phenotypic as well as genotypic levels, in general, grain yield (GY) had positively significantly correlated with biological yield (BY) and harvest index $(\mathrm{HI})$. Spike length (SL) had positively and significantly correlated with harvest index (HI) but negatively significantly correlated both at phenotypic as well as genotypic levels. Thousand seed weight (THSW) had negative significant correlation both at phenotypic as well as genotypic levels but negatively significantly correlated only at phenotypic level. Apart from the aforementioned traits, either positively or negatively associated traits, all the remaining traits indicated insignificant association. Genotypic correlation to phenotypic correlation were greater than the corresponding correlation coefficients, and this suggested that the apparent associations might be largely due to genetic causes and the environment played least role in the associations.

The observed variability within the twenty five six row barely genotypes in grain yield and other agronomic traits, indicates the potential for further improvement through directional selection and hybridization. The observed higher magnitudes of genotypic correlation coefficients in the same direction with the corresponding phenotypic correlations in most pairs of traits studied suggests that there is high probability for successfully predicting the performance of one trait from the actual performance of the associated trait through variable replacement.

\section{Conflict of Interest}

Conflict of interest none declared.

\section{REFERENCES}

Ajibade, S.R. (2000). Pedigree selection in cowpea. Nigeria Journal of Botany 13: 29-33. 
Jimera Haile, Hirpa Legesse and Rao

Akanda, M.A.L., Alam, M.S. and Uddin, M.M. (1998). Genetic variability, correlation and path analysis in composite maize. Bangladesh Journal of Agricultural Research 23 (1): 107-113.

Alam, K., Shabby, G., Chowdhry M.A., and Khaliq, I. (1992). Correlation of post-emergence characters with yield in barley. Pakistani Journal of Agricultural Science 29:449456.

Allard, R.W. (1960). Principles of Plant Breeding. John Wiley and Sons. Inc. New York.

Balcha Y. 2002. Assessment of stability and character association in bread wheat (Triticum aestivum L. em. Thell) genotypes. M.Sc. thesis. Alemaya University. Ethiopia.

Burton, G.W. and Devane, E.H. (1953). Estimating heritability in tall fescue (Festuca arundinacea) from replicated clonal material. Agronomy Journal 45:487-488.

Chilot Yirga, Fekadu Alemayehu and Woldeyesus Sinebo, (1998). Barley livestock production system in Ethiopia: An overview. In: Chilot Yirga, Fekadu Alemayehu, and Woldeyesus Sinebo (ed.) Barley-based Farming system in the highlands of Ethiopia. Ethiopian Agriculture Research Organization, Addis Ababa, Ethiopia, pp. 1-10.

CSA (Central Statistical Authority), 2013. Federal Democratic Republic of Ethiopia: Central statistics agency. Agriculture sample survey 2012/13(2005 E.C) (September-December 2013). Volume I. Report on Area and production of crops (Private peasant holding, Maher season). Statistical bulletin NO.532. Addis Ababa, May, 2013. Pp.12-117.

Desalegn, G. Bedada, D., Zewdie, A. and Solomon, G. (2000). Drought tolerance of some bread wheat genotypes in Ethiopia. African Crop Science 9(2): 385392.

Dewey, R. R. and Lu, K.H. (1959). A correlation coefficient analysis of components of crested Wheat grass seed production. Agronomy Journal 51: 515-518.

Donald, C.M. (1981). Competitive plants, communal plants, and yield in wheat crops. In: L.T. Evans and W.J. Peacock (ed.) Wheat Science-Today and Tomorrow. Cambridge University Press. U.S.A

Falconer, D.S. and Mackay, F.C. (1996). Introduction to Quantitative Genetics $4^{\text {th }}$ ed. Longman Group Limited Malaysia.

Getachew, B., Tesemma, T., Becker, H.C. and Merker, A. (1993). Variation and interrelationships of agronomic traits
Sci. Technol. Arts Res. J., April-June 2015, 4(2): 01-09 in Ethiopian tetraploid wheat landraces. Euphytica 71: 181-188.

Hamdi, A. and Erskine, W. (1990). Heritability of plant height and lowest pod height in lentil. Agricultural Research Review 68: 1497-1509.

ICARDA. (1990). Cereal improvement program annual report 1990. Aleppo Syria.

ICARDA. (2004). Crops varieties released, 1977-2007. Cereal and legume varieties icarda.org/Crops Varieties.htm, updated on 9 Jan. 2008.

Jena, S., and Neva, E. (1991). Variation in response to infection with Erysiphe graminis and Puccinia horde in some wild barley populations in the center of diversity. Euphytica 57: 133-140.

Johnson, H.W., Robinson, H.F. and Comstock, R.E. (1955b) Genotypic and Phenotypic Correlation in soybean and their implication in selection. Agronomy Journal 47:47-49.

Johnson, V. (1978). Breeding for yield and protein content in hard winter wheat. Cereal Foods World 23: 84-86.

Kumar, S. and Chauchan, B.P.S. (1979). Association analysis in the segregating population of linseed. Indian Journal of Genetics 39: 506-510.

Major, S. and Singh. G. (1996). Evaluation of yellow sarson germplasm at mid hills of Sikkim. Journal of Hill Research 9(1): 112-114.

Miller, P.A., Williams, H.C., Robinson, H.F. and Comstock, R.E. (1958). Estimates of genotypic and environmental variances and co-variances in upland cotton and their implication in selection. Agronomy Journal 43: 115-121.

Mondal, A.B., Sadhu, D.P. and Sarkar, K.K. (1997) Correlation and path analysis in bread wheat. Environment and Ecology 15(3): 537-539.

Munch, L. (1992). The contribution of barley to agriculture today and in the future. Barley Genetics 6:1099-1110. NC. USA

Nigussie Alemayehu (2001). Germplasm Diversity and Genetics of Quality and Agronomic Traits in Ethiopian Mustard (Brassica carinata A. Braun). Doctoral dissertation submitted to George-August University of Gottingen, Germany. 127p.

Sharma J.R. (1998). Statistical and biometrical techniques in plant breeding. New Age International (P) Limited, publishers. New Delhi. 432p. 